\title{
SIMULATION AND ASSESSMENT OF SHALE OIL LEAKAGE DURING IN SITU OIL SHALE MINING
}

\author{
ZHONG SHUANG ${ }^{(\text {a) }}$, TAO YI $^{(\text {b) }}$, LI CHENYANG ${ }^{(\text {a) }}$, \\ LI TONG ${ }^{()^{*}}$, ZHANG FENGJUN $^{(\mathrm{a})}$, SUN YANG $^{(\text {a) }}$
}

(a) Key Laboratory of Groundwater Resources and Environment, Ministry of Education, Jilin University, Changchun, 130021, China

(b) Inner Mongolia Yitai Group Co., Ltd, Department for Environmental Supervision, Ordos, 017000, China

(c) School of Stomatology, Jilin University, Changchun, 130023, China

\begin{abstract}
Whether there is a risk of shale oil leakage along the depleted wells or multi-level geological fractures during in situ oil shale mining was predicted using the geological data from the Songliao Basin and survey wells in Fuyu county of Jilin province, China. The simulation results obtained employing the Transport of Unsaturated Groundwater and Heat 2 (TOUGH2) software indicate that oil leakage along depleted wells would entail greater risks to the upper aquifer, while the leakage along multi-level geological fractures would involve higher risks to the lower aquifer close to the shale beds. The distributions of shale oil saturation under the original and 1.3-fold formation pressures are slightly different, and the pollution halo somewhat increased only in an aquifer 40-50 m underground. The shale oil saturation in the leaking channel may be 0 during the leaking process.
\end{abstract}

Keywords: shale oil, in situ mining, TOUGH2, leaking risk, saturation.

\section{Introduction}

Oil shale is a sedimentary rock of high ash and combustible organic material contents [1,2]. Oil shale contains more than $40 \%$ ash [3] and over $3.5 \%$ oil [4]. These values differ from the respective figures in coal and carbonaceous shale. Oil shale as an unconventional source of oil [5] is considered to be an alternative energy in the 21st century [6], due to its abundance and feasible exploitation and utilization [7]. Oil shale is distributed worldwide [8] and more than 600 deposits have been discovered in the USA [9], Australia, Estonia, China and other countries [5]. China possesses huge oil shale reserves (47.644 billion t) [10] and with this figure ranks fourth in the world

\footnotetext{
${ }^{*}$ Corresponding author: e-mail noforname11@gmail.com
} 
[11]. Oil shale in China was mainly formed in lacustrine environments, such as Tertiary oil shale in the Huadian and Fushun areas [12], and Cretaceous oil shale in the Songliao Basin [13].

At present, the retorting technology is being used to extract shale oil in many countries [14-16], while some of them produce shale oil on an industrial scale [11]. In recent years, in situ oil shale mining technology has become increasingly popular [17] because the traditional ectopic distillation technology has disadvantages, such as difficult mining, severe damage to formation, and high pollutant emission [18]. Depending on how the oil shale layer is heated, the in situ mining technology can be divided into three classes: conductive heating, convection heating and radiation heating [19]. Currently, the technology of conductive heating of a shale rammell mainly includes the in situ conversion process (ICP) from Royal Dutch Shell [20], the Electrofrac TM technology of Mobil, USA, and the geothermic fuel cells (GFCs) technology by Independent Energy Partners (IEP), USA. The technology of convection heating of a shale rammell chiefly employs the convection heating technology by Taiyuan University of Technology, China [18], the near-critical water dissolved heating technology of Jilin University, China, and the Crush and EGL technology from Chevron, USA [19]. The technology of radiation heating of a shale rammell mainly includes the radiofrequency technique by Lawrence Livermore National Laboratory (LLNL), USA, and the radio frequency/critical flow (RF/CF) technology of the Raytheon Company, USA. ICP has been used for field production in Colorado, USA, and has afforded good results [21]. However, shale oil leakage will pollute underground aquifers, since the in situ oil shale mining technology makes the shale oil stay in liquid form in underground shale layers for a long time.

The study area was located in the shale enrichment region in the Songliao Basin, Fuyu county, Northeast China. Together with the formation conditions and the in situ near-critical water dissolved heating technology, the authors simulated underground shale oil leakage by using the software Transport of Unsaturated Groundwater and Heat 2 (TOUGH2), aiming to provide reference to risk prediction and prevention during in situ mining and thereby to reduce the risk of environmental pollution.

\section{Geology of the study area}

The study area is located in the central depression part of the Songliao Basin. The folds and fractures in this area developed in the Cretaceous Formation by the Mesozoic Yanshan movement, and formed a short axis anticline and syncline, predominantly in north-east striking. The faults in the area mainly belong to the Second Songhua River normal fault striking north-west and roughly parallel to the Second Songhua River, and the normal fault in northeast striking with a steep angle [22]. The first significant event cut the 
Cretaceous strata. According to the top surface between the southern and northern Cretaceous strata of the Second Songhua River, the breaking distance is inferred to be $100 \mathrm{~m}$. The second event cut the Tertiary strata to break away about $20 \mathrm{~m}$. The geological stability analysis shows that many earthquakes happened around this area, among which the one having happened in 1919 in Qianguo, Jilin province, had a larger seismic magnitude and was less than $100 \mathrm{~km}$ from the study area.

According to the graph of a dynamic peak acceleration division of earthquakes in China, the dynamic peak acceleration in the study area was mainly estimated to be $0.1-0.2$, and the crustal stability is general. There have been formed several oil fields in Fuyu county.

The above analysis indicates that larger geological fractures more probably appear in the formation of the study area, so there are multi-stage geological fractures and depleted oil exploration wells in the continuous formation. Therefore, there is a risk of shale oil leakage along the geological fractures or depleted wells during in situ oil shale mining in this area.

\section{Simulation of shale oil leakage by TOUGH2}

\subsection{Introduction into TOUGH2}

TOUGH is a numerical program for simulating multiphase or multicomponent non-isothermal water flow and thermal migration, in a one-, twoor three-dimensional porous or fissured medium. The second version TOUGH2 has a very wide application range: geothermal storage engineering, disposal of nuclear waste, hydrology of saturated/unsaturated zone, environmental evaluation and repair, deep geological disposal of carbon dioxide, etc. [23].

The codes of TOUGH were developed by Lawrence Berkeley National Laboratory (LBNL), USA, in the 1980s. TOUGH2, which is written in standard FORTRAN77, can be operated on any platform with a suitable FORTRAN compiler. In the simulation of water system by TOUGH2, the spatial dimension of water system changes from micro- to basin scale, and the time scale changes from a few seconds to geological time. TOUGH2 is characterized by a modular program structure, open program code, discrete generality, and high solving efficiency [23]. The program provides 11 types of equation of state (EOS) modules depending on the characteristics of an actual simulation problem. In this study, the EOS8 module was adopted to simulate a two-phase flow movement of shale oil and water [24].

In the simulation, the TOUGH2 EOS8 module developed by Pruess et al. was used. The module adopts the integral finite difference method (IFD) for a discrete space [25] (Fig. 1). IFD provides a flexible geological medium discretization through the use of an irregular grid subdivision, and this method is suitable for simulating flow and migration in anisotropy and in different fracture rock systems. 


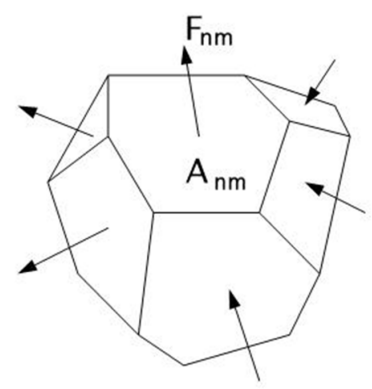

Fig. 1. Space discretization method of integral finite difference. [25]:

The governing equation of integral of mass and energy is expressed as

$$
\frac{d}{d t} \int_{V_{n}} M^{k} d V_{n}=\int_{\Gamma_{\mathrm{n}}} F^{k} \cdot n d \Gamma_{n}+\int_{V_{n}} q^{k} d V_{n} .
$$

The integration is over an arbitrary subdomain $V_{n}$ of the flow system under study, which is bounded by the closed surface $\Gamma_{n}$. The quantity M appearing in the accumulation term (left-hand side) represents mass or energy per volume, with $k=1, \ldots$, NK labeling the mass components (water, air, $\mathrm{H}_{2}$, solutes, ...), and $k=\mathrm{NK}+1$ heat "component". $F$ denotes mass or heat flux (see below), $q$ signifies sinks and sources, and $n$ is a normal vector on the surface element $d \Gamma_{n}$, pointing inward into $V_{n}$.

The general form of the mass accumulation term is:

$$
M^{k}=\phi \sum_{\beta} S_{\beta} \rho_{\beta} X_{\beta}^{\kappa} .
$$

The total mass of component $k$ is obtained by summing over the fluid phases $\beta$ (liquid, gas, NAPL). $\Phi$ is porosity, $S_{\beta}$ is the saturation of phase $\beta$ (i.e. the fraction of pore volume occupied by phase $\beta$ ), $\rho_{\beta}$ is the density of phase $\beta$, and $X^{k}{ }_{\beta}$ is the mass fraction of component $k$ present in phase $\beta$.

The advective mass flux is a sum over phases:

$$
\left.F^{k}\right|_{a d v}=\sum_{\beta} X_{\beta}^{k} F_{\beta} .
$$

Individual phase fluxes are given by a multiphase version of Darcy's law:

$$
F_{\beta}=\rho_{\beta} u_{\beta}=-k \frac{k_{r \beta} \rho_{\beta}}{\mu_{\beta}}\left(\nabla P_{\beta}-\rho_{\beta} g\right),
$$

where $\mu_{\beta}$ is the Darcy velocity (volume flux) in phase $\beta, k$ is an absolute permeability, $k_{r \beta}$ is a relative permeability to phase $\beta, \mu_{\beta}$ is viscosity, and $P_{\beta}$ is the liquid pressure of phase $\beta$. 
The discretization in space uses the integral finite difference (IFD) method. The discretization in time is implicit. The nonlinearity of Equation (1) results in difficulty to be solved directly. Therefore, the Newton-Rapson iteration is employed. Jacobian matrixes are evaluated by numerical differentiation. Linear equations are solved by direct methods for sparse matrices or iteratively by means of preconditioned conjugate gradients.

\subsection{Conceptual model}

On the basis of the results of field investigations and the information available on the side profile of a field geological exploration well, the generalized formation is obtained and the results are shown in Table 1. The aquifers are marked as $A_{a-b}$, where $a-b$ is the location underground. For instance, an aquifer located $60-100 \mathrm{~m}$ underground is marked as $\mathrm{A}_{60-100}$.

Table 1 shows that the humus aquifer $\mathrm{A}_{0-20}$ extends from the top of the formation downward to $20 \mathrm{~m}$, and then aquifers of mudstone and sandstone of varying thickness alternate from $20-305 \mathrm{~m}$ underground. $\mathrm{A}_{60-100}$ is a thick siltstone aquifer and $\mathrm{A}_{100-140}$ is a thick mudstone water-resistant aquifer. Other mudstone and siltstone layers are 15-35 m thick, while each layer is relatively thin. $\mathrm{A}_{305-380}$ is an oil shale aquifer close to the critical water under a high-temperature and high-pressure displacement layer of shale oil, with a mudstone layer as the underlying formation. The living drinking water sources in these layers are mainly the groundwater of $\mathrm{A}_{40-50}$ and $\mathrm{A}_{60-100}$, with a vertical distance of about $10 \mathrm{~m}$. In a relatively closed structure, the shale oil can stably exist for a long time during the heating and cracking of nearcritical water in in situ oil shale mining, but the presence of some depleted wells or a fault zone may become channels of shale oil leakage. Shale oil will leak to the upper aquifer along the fracture channel, and groundwater in various siltstone aquifers will suffer from pollution of different degrees during the process. Especially, the shallow aquifer is closely related to production and life, so it will have significant effects.

Table 1. Generalized formation of well 1

\begin{tabular}{|c|c|c|}
\hline Number & Thickness, m & Lithology \\
\hline 1 & $0-20$ & Muck \\
2 & $20-40$ & Mudstone \\
3 & $40-50$ & Siltstone \\
4 & $50-60$ & Mudstone \\
5 & $60-100$ & Siltstone \\
6 & $100-140$ & Mudstone \\
7 & $140-165$ & Siltstone \\
8 & $165-185$ & Mudstone \\
9 & $185-200$ & Siltstone \\
10 & $200-215$ & Mudstone \\
11 & $215-240$ & Siltstone \\
12 & $240-305$ & Mudstone \\
13 & $305-380$ & Oil shale \\
14 & $380-$ deep layer & Mudstone \\
\hline
\end{tabular}




\subsection{Determination of leaking patterns}

Two shale oil leakage ways were considered in the simulation: leaking along the depleted wells and leaking along multi-stage geological fractures. In the first case, shale oil leaks through the existing depleted well or a larger direct fracture, so it will pollute groundwater. In the second case, shale oil leaks through the existing normal or multilayer fault so that it pollutes groundwater. During in situ oil shale mining, the displacement of shale oil is implemented by injecting a high-pressure near-critical water flow. Previous research on formation stability shows that the empirical value of the formation fracture pressure is 1.5 times the original formation pressure, and in this case, the high-pressure fluid may break through the roof [24]. Therefore, in the simulation, the original $\left(P_{0}\right)$ and 1.3-fold $\left(P_{1.3}\right)$ formation pressures were chosen. The simulation scheme is shown in Table 2.

Table 2. Simulation scheme

\begin{tabular}{|l|c|c|}
\hline $\begin{array}{l}\text { Leakage } \\
\text { conditions }\end{array}$ & $\begin{array}{c}\text { Leakage ways } \\
\text { depleted wells }\end{array}$ & $\begin{array}{c}\text { Leaking along multi- } \\
\text { stage geological fractures }\end{array}$ \\
\hline $\begin{array}{l}\text { Formation pressure of oil shale } \\
\text { 1.3-fold the formation pressure of oil shale }\end{array}$ & $\begin{array}{l}\text { Scheme 1 } \\
\text { Scheme 2 }\end{array}$ & $\begin{array}{c}\text { Scheme 3 } \\
\text { Scheme 4 }\end{array}$ \\
\hline
\end{tabular}

\subsection{Model setup}

The conceptual simulation model can be generalized to a geological model that ranges from the surface to the oil shale layer $(0-310 \mathrm{~m})$ in a vertical and lateral extension of $700 \mathrm{~m}$ in level from the depleted wells. The outermost of this geological model is considered to be the boundary with constant pressure and constant temperature, and an oil plume will not affect the border during the simulation.

We assume there is no vertical infiltration, but the surface can transfer heat through conduction, and the formation pressure and temperature are in the untapped formations before the leakage. In addition, we consider that sandstone and mudstone do not contain oil before the leakage, so the oil content of sandstone will be higher than 0 after shale oil leakage. In order to maximize the leakage risk, the shale oil content in the oil shale layer is fixed and the leakage can be ignored considering the shale oil amount in oil shale layers. Namely, we suppose plenty of leakage sources during the simulation and predict a maximum leaking risk. The initial boundary conditions are shown in Table 3.

The system was simulated using a cartesian grid with uniform properties and considered as a homogeneous and isotropic original grating. It is vertically divided into 62 layers from the surface to $310 \mathrm{~m}$ underground, with each layer $5 \mathrm{~m}$ in thickness. At y direction, the model stretches $1400 \mathrm{~m}$ $(0-1400 \mathrm{~m})$ and is divided into 140 grids. At $\mathrm{z}$ direction, $\Delta \mathrm{y}=1.0 \mathrm{~m}$. The leaking point of the oil shale layer is set at $\mathrm{x}=700 \mathrm{~m}$ and the shale oil in the leaking point can leak upwards to the aquifers through the depleted wells or 
multilayer geological fractures. When shale oil leaks along the depleted wells, the diameter of each well is set to be $0.3 \mathrm{~m}$; when shale oil leaks along multilayer geological fractures, the fracture width is set to be $0.1 \mathrm{~m}$ and the horizontal distance is $50 \mathrm{~m}$. The grid number is 8680 , the geothermal gradient is $2.58^{\circ} \mathrm{C} / \mathrm{m}$, and the simulation time is two years.

In order to consider the highest leaking risk in case of shale oil leakage along the depleted wells (or a larger direct fracture), the wells pass through five mudstone aquifers: $\mathrm{A}_{50-60}, \mathrm{~A}_{100-140}, \mathrm{~A}_{165-185}, \mathrm{~A}_{200-215}$, and $\mathrm{A}_{240-305}$, and are all located at $\mathrm{x}=700 \mathrm{~m}$ in each mudstone layer, so shale oil can migrate up to $\mathrm{A}_{40-50}$ through the depleted wells. For shale oil leakage along multilayer geological fractures, however, the fractures are located $(\mathrm{x}=700-1400 \mathrm{~m})$ laterally, which is a vertical fracture connecting the aquifers from top to bottom. The fractures are at an interval of $50 \mathrm{~m}$ and pass through a mudstone layer. Shale oil can migrate up to $\mathrm{A}_{40-50}$ through the fracture.

The hydrogeological parameters were determined in field investigations and laboratory experiments. The formation pressure was determined by the hydrostatic pressure balance method, while the original formation temperature was obtained using the geothermal gradient. Parameters such as relative permeability and capillary pressure are from [26]. The detailed results are shown in Table 4.

Table 3. Initial boundary conditions

\begin{tabular}{|l|l|}
\hline Top of the model & $P=1$ bar, $T=13.5^{\circ} \mathrm{C}$ \\
Bottom of the model & $P=30$ bar, $T=21.5^{\circ} \mathrm{C}$ \\
Temperature $(T)$ & $\begin{array}{l}\text { Follow the geothermal gradient, } 2.58{ }^{\circ} \mathrm{C} \\
\text { Calculate by using the model according to the principle of hydraulic } \\
\text { Pressure }(P)\end{array}$ \\
balance \\
Fluid density
\end{tabular}

Table 4. Hydrogeological parameters of the model

\begin{tabular}{|c|c|c|c|c|}
\hline \multirow{2}{*}{$\begin{array}{l}\text { Sandstone } \\
\text { system }\end{array}$} & Porosity & 0.21 & Permeability & $5 \times 10^{-12} \mathrm{~m}^{2}$ \\
\hline & Rock density & $2600 \mathrm{~kg} / \mathrm{cm}^{3}$ & Rock compressibility & $4.5 \times 10^{-10} \mathrm{~Pa}^{-1}$ \\
\hline \multirow{2}{*}{$\begin{array}{l}\text { Mudstone } \\
\text { system }\end{array}$} & Porosity & 0.09 & Permeability & $5 \times 10^{-15} \mathrm{~m}^{2}$ \\
\hline & Rock density & $2580 \mathrm{~kg} / \mathrm{cm}^{3}$ & Rock compressibility & $4.5 \times 10^{-10} \mathrm{~Pa}^{-1}$ \\
\hline \multicolumn{2}{|c|}{$\begin{array}{l}\text { Saturation coefficient of heat } \\
\text { transfer }\end{array}$} & \multicolumn{3}{|c|}{$2.51 \mathrm{~W} /\left(\mathrm{m}^{\circ} \mathrm{C}\right)$} \\
\hline \multicolumn{2}{|c|}{$\begin{array}{l}\text { Relative liquid phase perme- } \\
\text { ability (Van Genuchten) }\end{array}$} & \multicolumn{3}{|c|}{$\begin{array}{l}k_{l r}=\sqrt{S^{*}}\left\{1-\left(1-\left[S^{*}\right]^{1 /}\right.\right. \\
S^{*}=\left(S_{l r}-S\right) /\left(1-S_{l r}\right)\end{array}$} \\
\hline \multicolumn{2}{|c|}{ Saturation of water residues } & \multicolumn{3}{|c|}{$S_{l r}=0.20$} \\
\hline \multicolumn{2}{|c|}{$\begin{array}{l}\text { Relative gas permeability } \\
\text { (Corey) }\end{array}$} & \multicolumn{3}{|c|}{$k_{r g}=(1-\widehat{S})^{2}\left(1-\widehat{S}^{2}\right), \widehat{S}=\left(S_{l}-S_{l r}\right) /\left(S_{l}-S_{l r}-S_{g r}\right)$} \\
\hline \multicolumn{2}{|c|}{ Saturation of gas residues } & \multicolumn{3}{|c|}{$\mathrm{S}_{\mathrm{gr}}=0.05$} \\
\hline \multicolumn{2}{|c|}{$\begin{array}{l}\text { Capillary pressure (Van } \\
\text { Genuchten) }\end{array}$} & \multicolumn{3}{|c|}{$P_{c a p}=-P_{0}\left(\left[S^{*}\right]^{-1 / m}-1\right)^{1-m}, S^{*}=(S l-S l r), P_{0}=\rho_{w g} / \alpha$} \\
\hline \multicolumn{2}{|c|}{ Index } & \multicolumn{3}{|c|}{$\mathrm{m}=0.4438$} \\
\hline
\end{tabular}




\section{Results and analysis}

Four models were constructed according to leakage cases. The simulation results of 30-, 60-, 120-, 182-, 365- and 730-day leakages were obtained.

\subsection{Shale oil leakage along the depleted wells}

The simulation of shale oil leakage along the depleted wells consists of two schemes: scheme 1 applies pressure $P_{0}$ (Fig. 2a), and scheme 2, pressure $P_{1.3}$ (Fig. 2b).

After two years of leakage, the leakage pollution halos under $P_{0}$ and $P_{1.3}$ (Fig. 2) are slightly different, but the pollution halo somewhat increased vertically in $\mathrm{A}_{40-50}$. The reason is probably that the increasing amplitude of oil shale formation pressure is smaller (about 0.3-fold) and shale oil viscosity higher, so the smaller pressure increase failed to greatly affect the oil migration.

As a result, the difference between scheme 1 and scheme 2 is small, and the shale oil leakages under two pressures are largely similar. Therefore, only shale oil leakage under $P_{1.3}$ is analyzed (Fig. 3).

While leaking along the depleted wells for 30 days (Fig. 3a), shale oil migrates to $\mathrm{A}_{40-50}$ by quickly penetrating each aquifer along the wells, which pollutes aquifers to a different extent. Meanwhile, shale oil is mainly distributed on the top of the aquifer, mainly because oil density is lower than that of water. With the extension of leaking time, the lateral migration distance of the oil halo increased constantly, and shale oil accumulation in each aquifer increased as well (Fig. 3b-e). After two years of continuing leakage in $\mathrm{A}_{60-100}$ (Fig. 3f), accumulation is maximized, while the lateral migration radius of shale oil is the largest, about $550 \mathrm{~m}$. Thus shale oil leaking along the depleted wells will harbor a higher pollution risk to the upper aquifer near the ground.

(a)

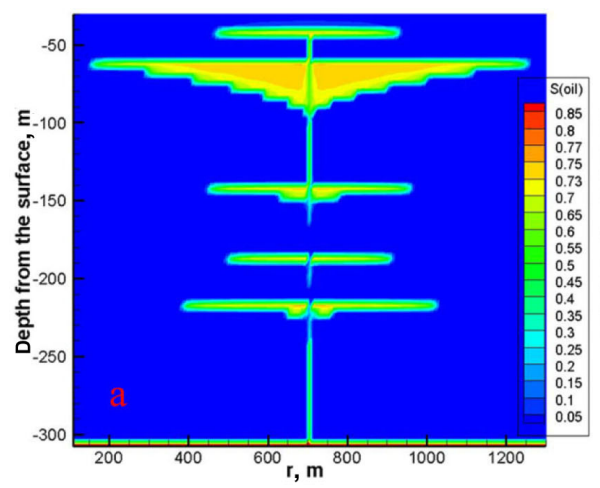

(b)

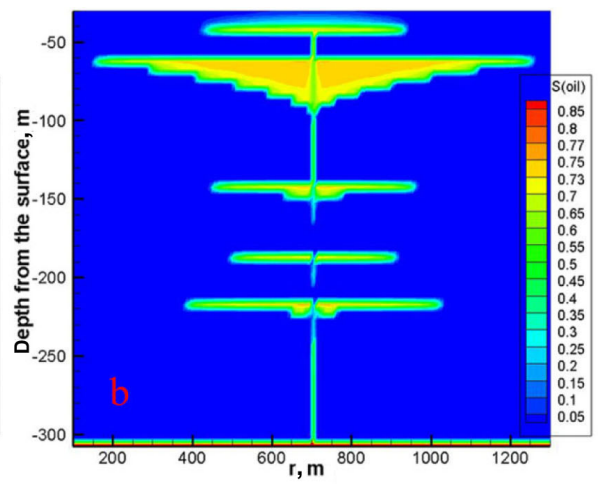

Fig. 2. Saturation distribution of shale oil leakage along the depleted well after 2 years (730 days), (a) under $P_{0}$, (b) under $P_{1.3}$. 

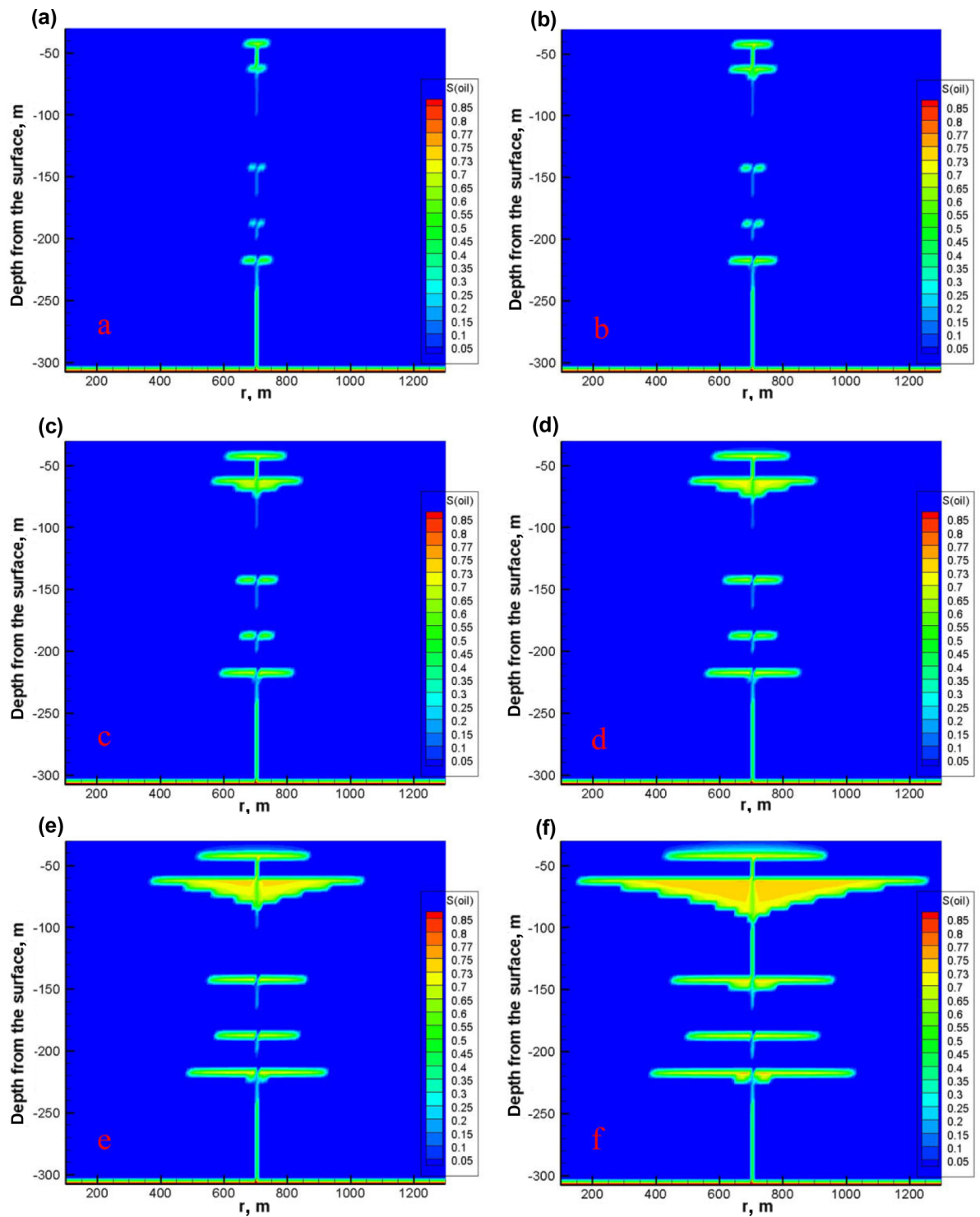

Fig. 3. Saturation distribution of shale oil leakage along the depleted well (1.3-fold the formation pressure) after (a) 30 days, (b) 60 days, (c) 120 days, (d) 182 days, (e) 365 days, (f) 730 days.

In a low-permeability mudstone layer, shale oil migrates mainly lengthways, but very slightly in the lateral direction, while for a higher-permeability sandstone layer, the lateral migration distance is longer. The depleted wells near the shale layer are full of oil, while during some periods of formation, its amount in the wells is almost 0 (Fig. 3). This is probably because the supply of plenty of shale oil from the oil shale layer makes its amount in the depleted bottom mudstone wells greater than 0 . Moreover, in 
the well located 100-140 $\mathrm{m}$ underground, the underlying aquifer will intercept part of shale oil and there is not enough oil leaking to the next aquifer through the high-permeability well fracture, thus resulting in the "disconnected" shale oil saturation in the depleted wells. The amount of oil in that fracture will be greater than 0 due to its constant upward leakage from the lower part and accumulation in $\mathrm{A}_{60-100}$ after a certain period of time.

Lateral migration distances of shale oil in aquifers are different and are closely related to aquifer thickness. The density of shale oil is smaller than that of groundwater, and shale oil rises from the bottom of the aquifer to its top under the conditions of density differences, so the lateral diffusion of shale oil also occurs during this process. We assume that the permeability of each aquifer is constant during the simulation, so the longitudinal migration time in a thick aquifer is longer, resulting in a longer lateral migration time along the aquifers, a longer migration distance and a larger retention volume. By comparing $\mathrm{A}_{215-240}$ and $\mathrm{A}_{140-165}$, which are of the same thickness, it is found that their lateral migration distances are substantially different, because the supplementary amount of shale oil in $\mathrm{A}_{215-240}$ is significantly greater than that in $\mathrm{A}_{140-165}$. Consequently, besides aquifer thickness, lateral migration distance is also affected by the supplementary shale oil amount.

\subsection{Shale oil leakage along the multi-stage geological fracture}

Simulation of shale oil leakage along the multi-stage geological fracture is also divided into two schemes: scheme 3 uses $P_{0}$ (Fig. 4a), and scheme 4, $P_{1.3}$ (Fig. 4b).

As the smaller increase of pressure had no significant effect on the higherviscosity oil migration, the leakage pollution halos under $P_{0}$ and $P_{1.3}$ are slightly different, whereas the pollution halo somewhat increased vertically in $\mathrm{A}_{40-50}$. Therefore, only shale oil leakage under $P_{1.3}$ is analyzed (Fig. 5).

(a)

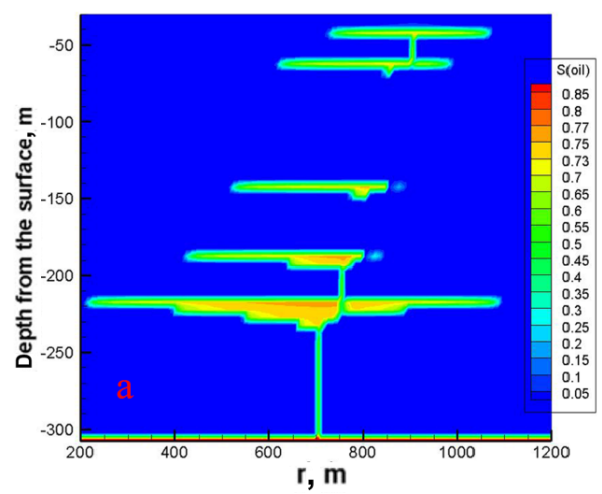

(b)

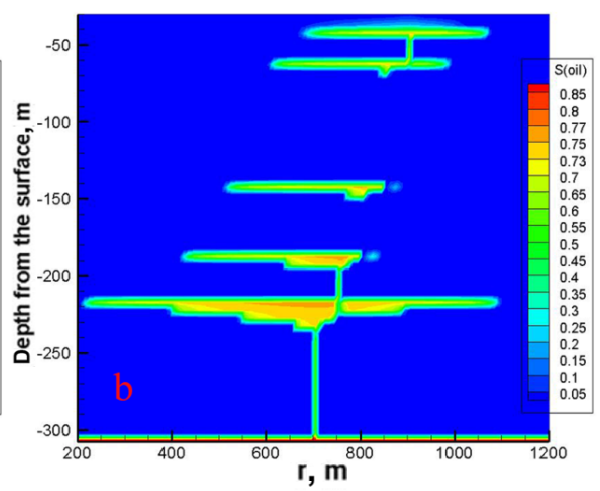

Fig. 4. Saturation distribution of shale oil leakage along the multi-stage geological fracture after 2 years (730 days), (a) under $P_{0}$, (b) under $P_{1.3}$. 

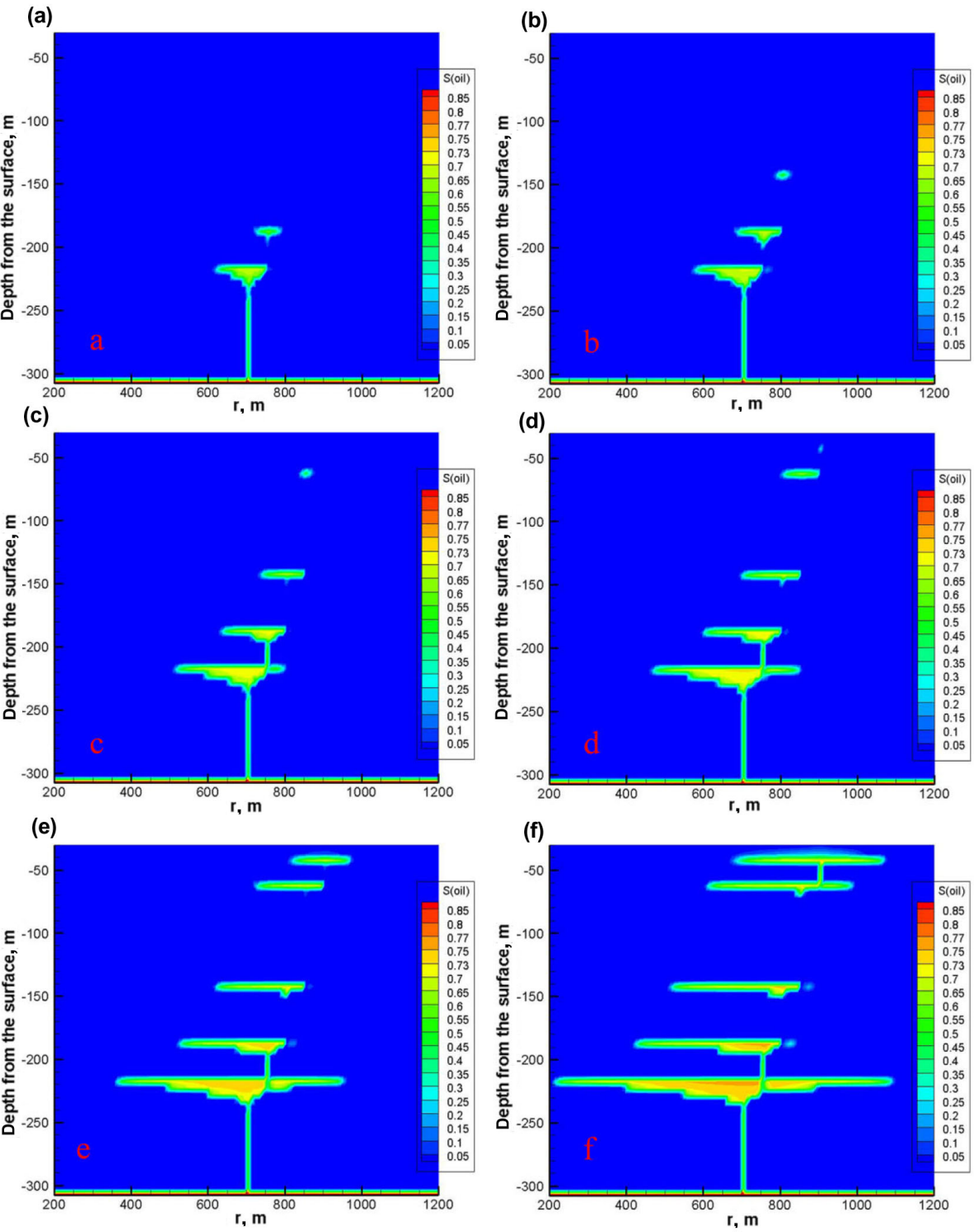

Fig. 5. Saturation distribution of shale oil leakage along the multi-stage geological fracture (1.3-fold the formation pressure) after (a) 30 days, (b) 60 days, (c) 120 days, (d) 182 days, (e) 365 days, (f) 730 days.

Shale oil migrates only to $\mathrm{A}_{185-200}$ within 30 days (Fig. 5a). As the leakage continues, shale oil keeps lateral migration to the upper aquifer through fractures and appears in $\mathrm{A}_{40-50}$ after 6 months (Fig. 5b-d). The migration rate of the vertical upward leakage along the multi-stage geological fracture is far lower than that along the depleted wells. 
With the extension of leakage time, the lateral and vertical migration distances of shale oil increase unceasingly, and shale oil is gradually accumulated from top to bottom in each aquifer, and the saturation is distributed from the center to the surrounding. After two years of continuous leakage, the maximum radius of lateral shale oil migration is about $400 \mathrm{~m}$ (Fig. 5f). Depicting the two-year leakage, Figure $5 \mathrm{f}$ shows that the shale oil accumulation in the lower aquifer is more intensive, especially in $A_{215-240}$. Therefore, there is a greater pollution risk to the shallower aquifer near the shale layer due to the shale oil leakage along the multi-stage geological fracture. Moreover, shale oil can migrate to the upper aquifer and, as a result, may cause its pollution.

A multi-stage geological fracture penetrates through the mudstone layer and connects aquifers. Shale oil first arrives in the bottom of the aquifer through the lower fracture, and then migrates both vertically and laterally in the aquifer. Only when shale oil migrates laterally to the next fracture of the aquifer, can it migrate to the upper aquifer through the fracture. In the latter case, the migration time of shale oil is longer than on its leaking along the depleted wells, which increases the interception of shale oil in the aquifer. The thickness of an aquifer and the mechanism of oil migration in it are different from those in depleted wells, resulting in the largest shale oil halo located in $\mathrm{A}_{215-240}$. This probably happens during the leakage through depleted wells when shale oil saturation in a supernatant fissure is almost 0 .

\section{Conclusions}

After two years of continuing leakage along the depleted wells, the shale oil accumulation is maximized in $\mathrm{A}_{60-100}$, the radius of the pollution halo is about $550 \mathrm{~m}$, and it will harbor a higher pollution risk to the upper aquifer near the ground. In comparison, after two years of continuing leakage along the multi-stage geological fracture, the shale oil accumulation is maximized in $\mathrm{A}_{215-240}$, the radius of the pollution halo is about $400 \mathrm{~m}$, and it will harbor a greater pollution risk to the lower aquifer near the oil shale layer.

When shale oil leaks along the depleted wells and multi-stage geological fracture, the distribution of its saturation is slightly different under $P_{1.3}$ and $P_{0}$, and the pollution halo increases a little only in $\mathrm{A}_{40-50}$. During the leakage, shale oil saturation may be 0 .

\section{Acknowledgments}

This work was financially supported by the National Potential Oil and Gas Resources (Oil Shale Exploration and Utilization Exploration) Innovation Research Project of China (Grant No. OSR-01), and the Key Laboratory of Groundwater Resources and Environment, Jilin University, Chinese Ministry of Education. 


\section{REFERENCES}

1. Han, X. X, Jiang, X. M., Wang, H., Cui, Z. G. Study on design of Huadian oil shale-fired circulating fluidized bed boiler. Fuel Process. Technol., 2006, 87(4), 289-295.

2. Sonibare, O. O., Jacob, D. E., Ward, C. R., Foley, S. F. Mineral and trace element composition of the Lokpanta oil shales in the Lower Benue Trough, Nigeria. Fuel, 2011, 90(9), 2843-2849.

3. Miao, Z. Y., Wu, G. G., Li, P., Meng, X. L., Zheng, Z. L. Investigation into copyrolysis characteristics of oil shale and coal. Int. J. Mining Sci.Technol., 2012, 22(2), 245-249.

4. Sun, P. C., Sachsenhofer, R. F., Liu, Z. J., Strobl, S. A. I., Meng, Q. T., Liu, R., Zhen, Z. Organic matter accumulation in the oil shale- and coal-bearing Huadian Basin (Eocene; NE China). Int. J. Coal Geol., 2013, 105, 1-15.

5. Na, J. G., Im, C. H., Chung, S. H., Lee, K. B. Effect of oil shale retorting temperature on shale oil yield and properties. Fuel, 2012, 95, 131-135.

6. Muhammad, A. F., El Salmawy, M. S., Abdelaal, A. M. Potential for upgrading El-Nakheil oil shale by froth flotation. Oil Shale, 2013, 30(1), 48-59.

7. Hakala, J. A., Stanchina, W., Soong, Y., Hedges, S. Influence of frequency, grade, moisture and temperature on Green River oil shale dielectric properties and electromagnetic heating processes. Fuel Process. Technol., 2011, 92(1), $1-12$.

8. Syed, S., Qudaih, R., Talab, I., Janajreh, I. Kinetics of pyrolysis and combustion of oil shale sample from thermogravimetric data. Fuel, 2011, 90(4), 1631-1637.

9. Tiwari, P., Deo, M. Compositional and kinetic analysis of oil shale pyrolysis using TGA-MS. Fuel, 2012, 94, 333-341.

10. Qun, Z., Dameng, L., Hongyan, W., Dexun, L., Shen, Y., Mingxiang, H., Lei, D. Identification of the depth range of in situ shale oil production. Oil Shale, 2013, 30(1), 19-26.

11. Wang, S., Jiang, X. M., Han, X. X., Tong, J. H. Investigation of Chinese oil shale resources comprehensive utilization performance. Energy, 2012, 42(1), 224-232.

12. Fu, X. G, Wang, J., Zeng, Y. H., Tan, F. W., Feng, X. L. REE geochemistry of marine oil shale from the Changshe Mountain area, northern Tibet, China. Int. J. Coal Geol., 2010, 81(3), 191-199.

13. Fu, X. G., Wang, J., Zeng, Y. H., Tan, F. W., He, J. L. Concentrations and modes of occurrence of platinum group elements in the Shengli River oil shale, northern Tibet, China. Fuel, 2010, 89(12), 3623-3629.

14. Kumar, R., Bansal, V., Badhe, R. M., Madhira, I. S. S., Sugumaran, V., Ahmed, S., Christopher, J., Patel, M. B., Basu, B. Characterization of Indian origin oil shale using advanced analytical techniques. Fuel, 2013, 113, 610-616.

15. Niu, M. T., Wang, S., Han, X. X., Jiang, X. M. Yield and characteristics of shale oil from the retorting of oil shale and fine oil-shale ash mixtures. Appl. Energ., 2013, 111, 234-239.

16. Wang, S., Liu, J. X., Jiang, X. M., Han, X. X., Tong, J. H. Effect of heating rate on products yield and characteristics of non-condensable gases and shale oil obtained by retorting Dachengzi oil shale. Oil Shale, 2013, 30(1), 27-47.

17. Youtsos, M. S. K., Mastorakos, E., Cant, R. S. Numerical simulation of thermal and reaction fronts for oil shale upgrading. Chem. Eng. Sci., 2013, 94, 200-213. 
18. Sun, K. M, Tan, J., Wu, D. The research on dynamic rules of crack extension during hydraulic fracturing for oil shale in-situ exploitation. Procedia Environmental Sciences, 2012, 12, Part B, 736-743.

19. Vinegar, H. J., Bass, R. M., Hunsucker, B G.. Heat sources with conductive material for in situ thermal processing of an oil shale formation, US 20040211554 A1.

20. Vinegar, H. Shell's in-situ conversion process. 26th Oil Shale Symposium, Golden, Colorado, USA, 16-18 October 2006, http://www.ceri-mines.org/ documents/R05a-HaroldVinegar.pdf.

21. Brandt, A. R. Converting oil shale to liquid fuels: energy inputs and greenhouse gas emissions of the shell in situ conversion process. Environ. Sci. Technol., 2008, 42(19), 7489-7495.

22. Xia, L., Fenjin, S., Mingli, S., Zhihong, W., Fuying, Z., Zehui, Z., Li, X., Feng, H. Geochemistry of deep coal-type gas and gas source rocks in Songliao Basin. Petrol. Explor. Develop., 2009, 36(3), 339-346.

23. Pruess, K. The TOUGH codes - a family of simulation tools for multiphase flow and transport processes in permeable media. Vadose Zone J., 2004, 3(3), 738-746.

24. Rutqvist, J., Birkholzer, J., Cappa, F., Tsang, C.-F. Estimating maximum sustainable injection pressure during geological sequestration of $\mathrm{CO}_{2}$ using coupled fluid flow and geomechanical fault-slip analysis. Energ. Convers. Manage., 2007, 48(6), 1798-1807.

25. Pruess, K., Oldenburg, C., Moridis, G. TOUGH2 User's Guide, Version 2.0. Lawrence Berkeley National Laboratory, Berkeley, California, 1999.

26. Xu, T., Kharaka, Y. K., Doughty, C., Freifeld, B. M., Daley, T. M. Reactive transport modeling to study changes in water chemistry induced by $\mathrm{CO}_{2}$ injection at the Frio-I Brine Pilot. Chem. Geol., 2010, 271(3-4), 153-164.

Presented by $\ddot{U}$. Rudi

Received December 13, 2013 